\title{
Los diccionarios en el mundo ELE: ayer, hoy y mañana (una reflexión desde la propia experiencia)
}

\author{
Concepción Maldonado González \\ Universidad Complutense de Madrid \\ mariaconcepcionmaldonado@pdi.ucm.es
}

Resumen: Dos preguntas clave deben responderse para poder abordar con éxito un proyecto lexicográfico didáctico pensado para la enseñanza del español como segunda lengua: ¿Deben los estudiantes de ELE consultar un diccionario monolingüe o uno bilingüe? ¿Por qué, si para el usuario el diccionario es siempre un instrumento al que se le exige una utilidad práctica inmediata, los lexicógrafos y profesores de ELE nos empeñanos en convertirlo en un medio con el que hacer ejercicios con objetivos de aprendizaje a largo plazo? De la respuesta que demos a ambas preguntas, y de la adecuación del trabajo lexicográfico a los tiempos actuales (es decir, a los tiempos de las obras de consulta en digital), dependerán el éxito o el fracaso de un diccionario ELE.

Palabras clave: ELE (español como Lengua Extranjera); Lexicografía; Diccionarios de aprendizaje.

\begin{abstract}
Two essential questions must be answered if we want to be successful when we work on a pedagogical lexicographical project specially designed to teach Spanish as a foreign language: Must foreign students consult a monolingual dictionary or a bilingual one? Why do lexicographers and teachers insist on the use of dictionary as a useful tool to learn Spanish over the long term, if users have always demanded the dictionary be a quick and effective way of solving immediate doubts? Only if we know with certainty the answer to these two questions, and only if we are prepared to assume that dictionaries also include digital versions, will we be able to deal with our task successfully.
\end{abstract}

Keywords: SFL (Spanish as a Foreing Language); Lexicography; Learner's dictionaries. 


\section{Introducción: Una reflexión desde la propia experiencia}

¿Por qué este subtítulo? ¿Por qué este empeño en matizar que lo que vamos a plantear no es fruto de estudios teóricos exhaustivos sino de la combinación de dichos estudios con su aplicación práctica en el trabajo lexicográfico? Pues por la sencilla razón de que las cosas cambian y lo que hace exactamente diez años (Maldonado 2002) nos pareció un planteamiento válido, innovador y avanzado es un planteamiento que hoy no nos satisface y que dejamos de lado por ineficaz y por caduco. Así de sencillo. Que nos encontramos en crisis, vaya. Y que aunque empezamos a vislumbrar por dónde creemos que puede ir la solución lexicográfica a los problemas que plantea el uso del diccionario en el aula de español para extranjeros (¿o es ese mismo concepto el que nos plantea la crisis?), no esperen ustedes leer aquí ninguna afirmación categórica (pocas veces nos atrevemos a hacerlas, pero mucho menos ahora y en este asunto).

Hagamos un poco de historia...

\section{Diccionario monolingüe vs, diccionario bilingüe}

A finales del siglo xx y a principios de este siglo xxi, los frutos que la lexicografía didáctica había dado en el ámbito escolar (gracias al revulsivo que en 1989 había supuesto la tesis del profesor Humberto Hernández), se empiezan a extender a la lexicografía didáctica monolingüe pensada para la enseñanza del español como segunda lengua ${ }^{1}$. El propio Humberto Hernández (1990) lanzaba en el I Congreso de ASELE una declaración de intenciones sobre cuál debería ser el modelo que debería seguir la lexicografía didáctica monolingüe para estudiantes extranjeros de español, un modelo que él mismo revisará quince años más tarde (Hernández 2005).

En la base de todas estas disquisiciones teóricas, y, de hecho, previo a ellas, encontramos un debate distinto: el de si los estudiantes de ELE deben consultar un diccionario bilingüe o uno monolingüe. Ya el profesor Rushtaller, entre otros, ha planteado antes esta cuestión; así que nos limitaremos a resumir lo planteado por él en el XV Congreso Internacional de ASELE en 2004. De un lado, la teoría:

1. En los años 90 son editados los diccionarios DiPELE (Moreno 1995), Salamanca (Gutiérrez Cuadrado 1996) y Clave (Maldonado 1997). Si bien solo los dos primeros son obras específicamente dirigidas a un público ELE, el uso que los estudiantes dieron a Clave lo incluyó también, por la vía de los hechos, dentro de esta categoría de diccionarios monolingües para el aprendizaje del español como segunda lengua. 
En lo que se refiere a la principal disyuntiva, la de optar por un diccionario monolingüe o por uno bilingüe, la mayoría de los profesores y expertos en materia de enseñanza de español como lengua extranjera coinciden en dar preferencia al primer tipo, al menos a partir del nivel intermedio, mientras que el bilingüe suele considerarse de utilidad únicamente en la fase inicial. (Rushtaller 2004: 1)

Del otro, la práctica: «De la opinión predominante entre especialistas y profesores parece discrepar radicalmente la de los propios usuarios» (Rushtaller 2004: 2 ). Rushtaller se pronuncia sin miedo y llega a afirmar que esa discrepancia sorprendente entre la opinión mayoritaria de expertos y profesores y la postura de los propios usuarios no puede deberse a la ignorancia de estos últimos ni a la casualidad, sino que solo puede ser consecuencia de ventajas prácticas reales muy concretas.

No hace falta que sigamos citando autoridades en la materia (cfr. Martín 1999: 13-18). Basta con que pensemos en cualquiera de nosotros cuando nos hemos enfrentado como estudiantes a una segunda lengua. ¿Alguno acudió a su primera clase de inglés, francés, alemán, chino o árabe provisto de un diccionario monolingüe? Y, a partir del tercer año de estudio, ¿alguno compró entonces por propia iniciativa ( $y$ no por el concepto de obediencia debida a las sugerencias del profesor), un monolingüe?

Y sigamos recordándonos a nosotros mismos, pero ya como profesores de español: ¿Cuántos alumnos han llegado a nuestras aulas con un monolingüe elaborado por una editorial española o hispanoamericana, en vez de con un bilingüe, tamaño bolsillo, y editado en su país de origen por una editorial lexicográfica de referencia?

Pues bien, recordémonos (a nosotros y a nuestros alumnos) más que satisfechos en la consulta de un diccionario bilingüe tanto por el hecho de obtener toda la información en un mismo volumen como por el hecho de que dicha información ha sido la mayoría de las veces de orden semántico (búsqueda de significados desconocidos). Admitámoslo: si cualquiera de nosotros acudíamos (y seguimos acudiendo) al diccionario bilingüe, en la mayoría de los casos, con el fin de obtener con rapidez información clara y precisa sobre la traducción de un significado, rara vez estaremos dispuestos a sacrificar esas exigencias de claridad, inmediatez y precisión a la posibilidad que un diccionario monolingüe nos brinda de desarrollar, a largo plazo una capacidad de comprensión lectora:

Para el usuario [la cursiva es nuestra], el diccionario es un instrumento al que exige utilidad práctica inmediata, no un medio de hacer ejercicios de forma indirecta y con objetivos a largo plazo. (Rushtaller 2004:89) 


\section{Diccionarios impresos}

Volvamos pues al año 2001. ¿Cómo concebíamos nosotros un diccionario de español para extranjeros a finales del siglo pasado (es decir, hace solo doce años)?

El título con el que editamos nuestro repertorio lexicográfico fue, expresamente, Diccionario de español para extranjeros. ¿Hacen falta más precisiones? ¿No queda clara ya cuál fue nuestra toma de posición: ¡siempre al lado de la acertada y rigurosa teoría lexicográfico-didáctica, por supuesto! (un monolingüe); no del lado de lo que los usuarios, en su ignorancia, osan pedir... (un bilingüe).

Además, y dada la fecha, muchas de las características de la planta se derivaron de su concepción editorial como un diccionario en papel (porque, aunque hoy nos pueda extrañar, hace solo diez años los diccionarios eran todavía cualquier obra en papel en la que los contenidos se presentaran ordenados alfabéticamente).

\subsection{Cuestiones relativas al orden alfabético}

a) Seguiríamos el orden alfabético universal (el que incluye la $c h$ y la $l l$ en la $c$ y la $l$, respectivamente).

b) Los lemas sin tilde aparecerían siempre antes que los lemas con tilde. Así, por ejemplo, los artículos futbol, chofer y video (formas utilizadas en América) preceden a los artículos fútbol, chófer y vídeo; del mismo modo, parque o mama preceden a parqué o a mamá.

c) Si una palabra tiene diferentes formas, se podría buscar por cualquiera de ellas: psicología/sicología, translúcido/traslúcido, mayonesa/mahonesa, y desde la palabra menos usual (sicología, traslúcido y mahonesa) se remitiría a la más usual (psicología, translúcido y mayonesa).

d) Las abreviaturas se alfabetizarían sin tener en cuenta los puntos ni los espacios en blanco (la abreviatura admon., por ejemplo, estaría entre los lemas admitir y admonición); y la abreviatura apdo., entre los lemas apátrida y apeadero.

e) Las locuciones se incluirían en el artículo de su primera palabra fuerte gramaticalmente, según el siguiente orden de prioridad: sustantivo, verbo, adjetivo, pronombre, adverbio (así, por ejemplo, la locución no dar un palo al agua aparecería definida en palo y no en dar). Además, en caso de ser varias, aparecerían al final del artículo y por estricto orden alfabético. Ejemplo:

pa+lo s.m. 1 Trozo de madera más largo que grueso, generalmente cilíndrico y fácil de manejar: Recogieron palos secos para encender fuego. 2 Golpe dado con un trozo de madera de este tipo: Le dieron una paliza y casi lo matan a palos. 3 col. Experiencia difícil y desagradable porque supone un fuerte daño o un gran 
perjuicio: La muerte de su padre fue un gran palo para él. + Se usa más con los verbos dar, llevar o recibir. 4 col. Madera: El pirata tenía una pata de palo. 5 En una embarcación, cada uno de los maderos largos y redondos que sirven para sostener las velas: El fuerte viento derribó varios palos de la nave. + SIN. árbol. 6 En la baraja, cada una de las cuatro series o clases en que se dividen los naipes: Los palos de la baraja española son bastos, copas, oros y espadas. 7 En una letra, trazo que sobresale hacia arriba o hacia abajo: La ' $p$ ' tiene un palo hacia abajo. 8 DEP. En una portería, cada uno de los postes o maderos laterales que sujetan el travesaño o madero superior. $9 \mathrm{DEP}$. Instrumento con el que se golpea la pelota en algunos deportes: un palo de golf. 10 Lo que resulta muy delgado y alargado: Está tan delgada que no tiene piernas sino palos. 11 Amér. Árbol: Toda esta zona está llena de palos de canela. 12 || a seco; col. Sin más o sin nada accesorio: Se tomó el filete a palo seco, sin patatas ni ensalada. || dar algo; col. Ser desagradable o molesto: Me da palo decirte la verdad, pero tienes que saberla. I| dar palos de ciego; col. Actuar sin saber exactamente cuáles serán las consecuencias: Creía que estaba dando palos de ciego, pero al final encontré la solución. || no dar un al agua; col. Vaguear y holgazanear: No digas que estás cansado, porque no bas dado un palo al agua. || dulce; raíz del paloduz: Del palo dulce se obtiene un jugo muy utilizado en medicina. $\| \sim$ mayor; el más alto y que sostiene la vela principal: $E l$ marinero subió al palo mayor. $\|$ santo; madera de un árbol tropical americano, de color generalmente oscuro y muy dura, que se utiliza en ebanistería: El palo santo es la madera del guayacán.

f) Los espacios en blanco no contarían para la ordenación alfabética: la locución a posteriori se encontraría entre los lemas apostatar y apostilla; y boy scout estaría entre boys y bozal.

g) Si la palabra fuerte no funciona en la lengua independientemente, la locución iría dentro de un lema formado por esa palabra (la locución a nado estaría en el artículo nado).

na+do || a ; nadando: Se atrevió a cruzar el río a nado.

b) En los casos de locuciones latinas o extranjeras, se incluirían por orden alfabético y el lema del artículo estaría formado por la locución entera, ordenada por la primera palabra (in albis iría entre los lemas inalámbrico e inalienable).

Sí, ya sabemos que a muchos de ustedes todas estas disquisiciones sobre el orden alfabético les parecen arcaicas y obsoletas desde el momento en que el usuario ya concibe las obras de consulta en soporte digital; pero si les traemos aquí estos criterios de orden alfabético es porque, en aquel entonces, su aplicación coherente o no era uno de los baremos de calidad aplicables a la valoración de una 
obra lexicográfica. Piensen, de hecho, que pocas editoriales trabajaban con bases de datos y programas de ordenación alfabética automatizados, por lo que el error humano y la disparidad de criterios en una misma obra eran algo habitual.

\subsection{Selección del lemario}

Volvamos un momento al debate anterior sobre el uso de diccionarios bilingües o monolingües en el aprendizaje de una segunda lengua. El profesor Alvar, en la conferencia inaugural Los diccionarios bilingües y el aprendizaje de la lengua del Congreso Mundial de Profesores de Español (COMPROFES) pronunciada el pasado 21 de noviembre de 2011, opinaba que el uso de los diccionarios monolingües en el aprendizaje de una segunda lengua ha estado tradicionalmente basado en el hecho de que estos son mucho más abundantes en número de entradas y acepciones; y que así, frente a unas 50.000 entradas en cada mitad de un bilingüe, un monolingüe ofrecería unas 80.000 entradas. Y, continuaba, esto habría llevado a que en los niveles avanzados (en C1 y C2) se prefiera el uso de monolingües, dado, además, su carácter más normativo y el hecho de que, por tradición histórica, recogen palabras y realidades antiguas, frente a los bilingües, que dedican mayor atención al uso del momento y al léxico general (con especial hincapié en lo coloquial y en lo vulgar). ${ }^{2}$

Pues bien, diez años antes de estas afirmaciones, cuando nosotros tuvimos que definir el lemario de nuestro diccionario, contradijimos de lleno este planteamiento tradicional: creemos que lo que el profesor Alvar plantea alude a los monolingües cuyos destinatarios son los hablantes nativos de una lengua (aunque luego esos repertorios monolingües caigan en manos de estudiantes de español dispuestos a extraer de ellos información necesaria para el aprendizaje del español como segunda lengua). Y esa realidad no se correspondería en absoluto con los criterios de selección de un lemario concebido desde su inicio como un repertorio útil y pensado ex profeso para estudiantes de español como lengua meta.

En ese sentido, pues:

a) Se incluían las palabras más usuales del léxico actual entonces, y se desechaban, en cambio, términos y usos anticuados. No importaba que dichas palabras de uso fueran neologismos aun no registrados en el repertorio académico o extranjerismos sin adaptar a la ortografía ni a la pronunciación del español si su uso estaba documentado en la lengua diaria. Ejemplos:

\footnotetext{
2. Según el profesor Alvar, ese carácter normativo no impide que, dado que ni siquiera en esos niveles avanzados se conoce el AFI, la transcripción siga siendo información que se margina. En cambio, la abundancia de información gramatical (en el mismo artículo lexicográfico, o en cuadros y apéndices complementarios), se espera que sí que ayude a unos estudiantes que se supone que conocen peor los pilares gramaticales.
} 
an+ti+do+pa+je (pl. antidopaje) adj.inv. Que persigue o castiga la administración de sustancias estimulantes en el deporte: Hicieron un control antidopaje después de la carrera de atletismo.

chat s.m. En internet, charla o tertulia simultáneas que mantienen varios usuarios: Me be metido en un chat de literatura.

ci+ber+ca+fé s.m. Local o establecimiento provisto de sistemas informáticos para navegar por internet: Estuve toda la tarde navegando por internet en un cibercafé.

bí.fi+dus (pl. bifidus) s.m. Bacilo con propiedades dietéticas: un yogur con bifidus.

funky s.m. Música moderna popular, parecida al jazz y de ritmo fuerte: Mis amigos van a una discoteca donde solo ponen funky. + SIN. funk. + Pron. [fánki].

b) Se incluían también más de dos mil americanismos. De hecho, el título del diccionario iba acompañado en la primera de cubierta del subtítulo Con el español que se habla hoy en España y en América Latina . Veamos algunos ejemplos:

a+e+ro+mo+za s.f. Amér. Azafata de aviación: Mi prima es aeromoza en las líneas aéreas chilenas.

a+filche s.m. Amér. Cartel o póster: Las paredes estaban cubiertas de afiches.

a+gri+par+se v.prnl. Amér. Comenzar a tener la gripe: Ayer sali cuando estaba lloviendo y me agripé. + Conjug. $\rightarrow$ Hablar (4). + Se usa también en Canarias.

ba+cán, ca+na (pl. bacanes, nas) adj. 1 Amér. col. Elegante o de categoría: un hotel bacán. adj./s. 2 Amér. col. Que vive sin privaciones y gozando de una buena posición social: Vivía como un bacán.

ben+ci+na s.f. Amér. Gasolina.

em+pa+ni+zar v. Amér. Empanar: Este pan molido es para empanizar los bistés. + La $z$ se cambia en $c$ delante de $e \rightarrow$ UTILIzar (79).

gua+chi+mán (pl,guachimanes) s.m. Amér. Vigilante: Los guachimanes vigilaron toda la noche. + Se usa también en Canarias.

mo+les+to+so, sa adj. Amér. col. Molesto: No te aguanto porque eres bien molestoso.

no+ti+cie+ro s.m. Amér. Informativo o programa de noticias: Me enteré de lo que babía sucedido por el noticiero.

par+que+ar v. Amér. Aparcar: Parquearé el carro donde pueda + Conjug. $\rightarrow$ HABlar (4).

quiú +bo+le interj. Amér. col. Expresión que se usa para saludar o para preguntar algo llamando la atención: Quiúbole, ¿cómo estás?

3. Las razones de optar por el término América Latina (que incluye Brasil) en vez de por Hispanoamérica (que solo alude a los países de habla hispana) creo que queda clara cuando nos movemos en el ámbito empresarial (no académico) de ELE... 
No es este el momento de aclarar por qué en este diccionario recurrimos a la marca Amér. en vez de a la fórmula En zonas del español meridional, utilizada en Clave, y con la que se describía esa norma del sur peninsular español, Canarias y América Latina, frente a la norma castellana ${ }^{4}$. No obstante, sí convendría recordar que para la selección de esos más de 2000 términos se contemplaron los siguientes criterios (Maldonado 2002: 7):

- Que la voz o acepción tuviera un frecuente uso escrito en publicaciones periódicas y obras literarias de autores de este ámbito lingüístico

- Que hubiera coincidencia entre distintas variedades de este español de América Latina (así, botar en el sentido de 'tirar, echar o arrojar' se usa en el español de Argentina, Chile, Colombia, Ecuador, Guatemala, México, Nicaragua, Puerto Rico, Santo Domingo y Venezuela).

+ Que tuvieran un uso generalizado en zonas del español de América Latina de gran peso demográfico (México, Argentina, Colombia, Perú, Venezuela, Chile, Cuba...)

c) Se recogían y registraban siglas y abreviaturas, ya que un hablante extranjero no tiene por qué distinguir unas de otras y, ni siquiera, algunas de ellas de los nombres comunes: ¿cómo saber en un texto que admón., es una abreviatura y no un sustantivo? ¿O cómo interpretar iva, ave, ipc o dni, más usados ya como comunes que como siglas?

admón. Abrev. de administración.

avda. Abrev, de avenida.

AVE Sigla del tren de Alta Velocidad Española.

c. Abrev, de calle.

C.P. Abrev de código postal.

c/c Abrev. de cuenta corriente.

DNI s.m. Sigla de Documento Nacional de Identidad.

GEO s.m. Sigla de Grupo Especial de Operaciones.

IPC s.m. Sigla de Índice de Precios al Consumo.

IVA s.m. Sigla de Impuesto sobre el Valor Añadido.

\footnotetext{
4. Sobre la definición de las dos normas del español como una norma castellana (la del centro-norte peninsular) y una norma meridional (la del sur peninsular, Canarias y América Latina), donde la primera estaría caracterizada fundamentalmente por la existencia de la oposición s/ceta en el plano fonológico, y la distinción vosotros/ ustedes en el morfológico; y la segunda, por la ausencia de estas oposiciones, ausencia que da lugar al fenómeno del seseo, a la ampliación semántica del pronombre ustedes (plural de tú y de usted), al uso de vos en vez de tú (fenómeno característico de América Latina y que se conoce con el nombre de voseo) y a otros hechos gramaticales que lleva aparejados la ausencia del pronombre vosotros, pueden verse Hernández (1997) y Carriscondo (2012).
} 
ONG s.f. Sigla de Organización No Gubernamental.

$\mathrm{Sr}_{*}, \mathrm{Sr}_{*}{ }^{\mathbf{a}}$ Abrev, de señor, señora.

tfno. Abrev. de teléfono.

Vd. Abrev, de usted.

d) Se incluyó de forma exhaustiva un listado de los prefijos y sufijos más productivos en español, porque su inclusión permitía ahorrar un montón de espacio (tengan en cuenta que el ahorro de espacio era el principal obstáculo de la lexicografía cuando la lexicografía consistía en elaborar obras en papel). Obsérvese cómo en los siguientes ejemplos cada valor semántico de estos morfemas derivativos iba ejemplificado con formas derivadas usuales en español:

-a+je Sufijo que indica acción y efecto (aterrizaje), lugar (hospedaje) o conjunto ( $r a-$ maje).

an+ti- Prefijo que significa 'oposición' (anticlerical, antinatural, anticonstitucional), 'protección contra' (antigás, antirrobo), 'prevención contra' (anticoncepción, antideslizante) o 'lucha contra' (antidisturbios, antidepresivo).

bi- Elemento compositivo que significa 'dos': bilateral, bisexual, bipartidismo, bianual. + Puede adoptar la forma bis-(bisabuelo) o biz-(biznieto).

-ción Sufijo que indica acción y efecto: acusación, demolición.

con- Prefijo que significa 'reunión,' 'cooperación' o 'compañía': condiscípulo, confraternidad, conciudadano. + Ante $b$ o $p$, adopta la forma com-: combinar, compadre.

des- Prefijo que indica negación (desconfiar, desagradar), privación (desacuerdo, desagrado), exceso (deslenguado), 'fuera de' (destiempo, deshora) o acción inversa a la expresada por la palabra raíz (desvestir, desobediencia). + Las palabras que comienzan por este prefijo admiten separación silábica a final de línea, pero admiten también la separación por el prefijo: de-sánimo o des-ánimo.

-e+ro, -e+ra Sufijo que indica oficio (librero, panadero) o relación (ganadero, sopero).

-fo+bia Elemento compositivo que indica aversión: claustrofobia, agrofobia.

-ín, -i+na Sufijo que indica menor tamaño (pequeñin, neblina), origen o patria (mallorquin, menorquina) o agente (bailarin, andarina).

ra+dio- Elemento compositivo que significa 'radiación' o 'radiactividad' (radioterapia, radiología) o que indica relación con la radiodifusión (radionovela, radioteléfono, radiotaxi).

De todas formas, si bien en el caso de los prefijos la búsqueda por orden alfabético era natural e intuitiva (con-, por ejemplo, aparecía entre la preposición con y el adjetivo conativo; o anti-, entre antetitulo y antiabortista), en la inclusión de sufijos, por el contrario, su ordenación alfabética no correspondía con el orden al- 
fabético natural (así, por ejemplo, -ble se incluía entre blazer y bledo; -mente entre mente y mentecatería; y -ción entre ciña (del verbo ceñir) y cipayo (un soldado indio de los siglos xvin y xix al servicio de una potencia europea). Y eso parece evidente que en una ordenación alfabética recogida en un soporte impreso plantea más inconvenientes que ventajas...

e) Se incluyeron también como lemas las formas verbales irregulares que no se identifican claramente con su infinitivo.

$$
\begin{aligned}
& \text { an+du+ve v. irreg. } \rightarrow \text { ANDAR (I3). } \\
& \text { su+pe v.irreg. } \rightarrow \text { SABER (70). } \\
& \text { yen+do v. irreg. } \rightarrow \text { IR (44). }
\end{aligned}
$$

ab+suel-to, ta part. irreg. de absolver.

Y no pensemos solo en casos de clara dificultad en la búsqueda para un hablante no nativo como anduve (de andar), supe (de saber), yendo (de ir), o absuelto (de absolver), sino que procedimos a hacer un listado con todas las formas flexivas de todos los modelos de conjugación verbal, y a ordenar esas formas alfabéticamente. Se nos podrá preguntar ahora si las herramientas informáticas permiten realizar estas tareas sin apenas esfuerzo, ¿dónde radicaba la dificultad entonces? En la selección de cuáles de dichas formas valía la pena que ocuparan espacio en papel y cuáles eran, en cambio, un desperdicio de líneas.+. (entre dar y doy hay 72 páginas).

f) Y este planteamiento se hizo extensivo a cualquier tipo de variación flexiva o derivativa cuya semejanza formal con la palabra raíz no sea mucha, lo que incluye, por ejemplo, el tratamiento de muchos superlativos irregulares como lemas de este diccionario: y, como señalábamos antes, no pensemos solo en infimo (superlativo de malo, o de bajo); o en celebérrimo (de célebre), sino que igualmente incluíamos formas como calentísimo (de caliente), ya que el orden alfabético dejaba el superlativo muy lejos del adjetivo a partir del cual estaba formado (exactamente, dos páginas, 117 líneas, y 20 palabras más adelante).

g) Las palabras homónimas se incluían como acepciones distintas dentro de un mismo artículo. Por ejemplo, en el lema banco se encontraba la acepción de 'asiento' y la de 'organismo que comercia con dinero', aunque etimológicamente proceden de palabras distintas. Del mismo modo, los sustantivos femeninos (pata) se encuentran dentro de su correspondiente forma en masculino y femenino (pato, ta), aunque, para facilitar su búsqueda, en el sustantivo femenino cafetera aparece una remisión al artículo en que se encuentra cafetero, ra. La razón parece evidente: si ni siquiera los hablantes nativos somos capaces de diferenciar palabras homónimas y palabras polisémicas cuando no poseemos profundos co- 
nocimientos de historia del español y de la etimología de las palabras, ¿cómo vamos a exigir ese conocimiento a un estudiante de español como segunda lengua? ca+fe+te+ra s.f. Véase cafetero, ra.

ca+fe+te+ro, ra adj. 1 Del café o relacionado con él: un país cafetero. adj./s. 2 Referido a una persona, que es muy aficionada a tomar café: Es muy cafetero, por eso siempre pide café. Los cafeteros solemos tomar muchos cafés al día. $z$ s. 3 Persona que se dedica a la recolección o al comercio del café: Muchos cafeteros son jornaleros temporales. s.f. 4 Máquina o aparato para hacer café, o recipiente para servirlo: una cafetera de acero inoxidable. $5 \mathrm{col}$. Vehículo viejo y que no funciona bien: Esta cafetera no arranca ni a la de tres.

ca+za+do+ra s.f. Véase cazador, dora.

ca+za+dor, do+ra adj./s. 1 Referido a algunos animales, que por instinto persiguen y cazan a otros: un animal cazador. El águila es una cazadora con garras. adj./s. 2 Aficionado a la caza o que se dedica a esta actividad: Su abuelo era cazador. Los cazadores salieron a cazar muy temprano. $\mathbf{\text { s.f. }} 3$ Prenda de abrigo corta y ajustada a la cintura: Me be comprado una cazadora de cuero.

mer+lu+za s.f. Véase merluzo, za.

mer+lu+zo, za adj./s. 1 col. Referido a una persona, torpe o de escasa inteligencia: Este joven merluzo no sabe ni rellenar el impreso. Déjame terminar a mí, que tú eres una merluza. s.f. 2 (macho/hembra) Pez marino comestible, de cuerpo simétrico y alargado, con dos aletas dorsales y una anal, la barbilla muy corta y los dientes finos: Comeremos merluza rebozada. 3 col. Borrachera: Anoche se cogió una merluza tremenda.

pa+ta s.f. Véase pato, ta.

pa+to, ta s. 1 Ave palmípeda, de pico aplanado más ancho en la punta que en la base, cuello corto y patas pequeñas: En el estanque del parque hay patos. + SIN.

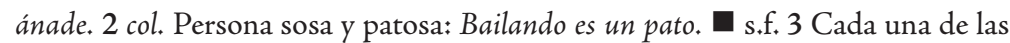
extremidades de un animal: Los perros tienen cuatro patas. o Cuando va delante de una palabra para formar compuestos, adopta la forma pati-: paticojo. $4 \mathrm{col}$. Pierna de una persona: Tiene las patas muy largas. + Cuando va delante de una palabra para formar compuestos, adopta la forma pati-: patizambo. 5 Pieza que sirve como base o apoyo de algo, esp. de un mueble: La mesa tiene una pata rota. o Cuando va delante de una palabra para formar compuestos, adopta la forma pati-: paticorto. 6 Amér. Etapa: La primera pata de este proyecto ya se cumplió. 7 Amér. col. Desfachatez o descaro: Siempre sale con alguna pata en las ocasiones más 
inoportunas. 8 || a cuatro patas; apoyándose en el suelo con las manos y los pies o las rodillas: andar a cuatro patas. || a la pata coja; apoyado sobre un pie y con el otro en el aire: saltar a la pata coja. || a la pata la llana; llanamente, con naturalidad o con confianza: Podemos hablarnos a la pata la llana. II a pata; col. A pie o andando: Volví a casa a pata. || de pata negra; 1 Referido esp. a un jamón, que es de una raza de cerdo ibérico que destaca por su gran calidad: Hemos tomado una ración de jamón de pata negra. 2 col. Que es de una calidad excepcional: Me han traído unos chocolates de pata negra. || estirar la pata; col. Morir. || mala pata; mala suerte. || meter la pata; col. Hacer o decir algo poco acertado: Metió la pata y descubrió nuestro secreto. || pagar el pato; col. Sufrir el castigo de algo sin merecerlo: ¿Por qué siempre tengo yo que pagar el pato? || pata de gallo; 1 Arruga con tres surcos divergentes que se forma en el ángulo externo del ojo a medida que avanza la edad de una persona: Esas patas de gallo indican que pasa de los cuarenta. 2 Tejido y dibujo en dos colores formado por figuras cuadrangulares y cruzadas que recuerdan las huellas de gallos y gallinas: Llevaba un traje de pata de gallo. || pata de rana; Amér. Aleta para bucear: Cuando voy a la costa siempre me llevo mis patas de rana. || patas arriba; desordenado o al revés: Tenía la casa patas arriba. || poner a alguien de patas en la calle; col. Echarlo de algún lugar, generalmente de malas maneras: Armaron un escándalo en el bar y los pusieron de patas en la calle. o Se usa mucho con el diminutivo poner de patitas en la calle. || ser el patito feo; col. Ser despreciado o ser poco valorado: Soy el patito feo porque soy la que peor juega al baloncesto.

\subsection{En lo relativo a la información incluida en cada artículo}

a) Se decidió incluir la partición silábica de todos los lemas (femeninos, incluidos), en el caso de los lemas con flexión de género. Con ello ayudaríamos a los usuarios a saber cómo se separa una palabra al final de renglón (lo creamos o no, a veces seguimos escribiendo a mano y nos atrevemos a mandar una postal, incluso...). Pero también, y sobre todo, le ayudaríamos a aplicar las sencillas reglas de acentuación del español. Porque solo si sabemos que dos vocales cerradas son siempre diptongo, las pronunciemos como las pronunciemos, podremos entender por qué jesuita o constituido no llevan tilde en la i.Y, del mismo modo, solo si sabemos que dos vocales abiertas son siempre hiato en español, las pronunciemos como las pronunciemos, podremos entender por qué línea lleva tilde en la -i (porque es esdrújula, ni más ni menos; aunque todos la sintamos como grave).

gra+fi-te+ro, ra s. Persona que se dedica a hacer pintadas: Un grafitero ha sido detenido por pintar un vagón de metro. 
le+ón, o+na (pl. leones, nas) s. 1 Mamífero felino y carnicero de pelo amarillo rojizo, dientes y uñas fuertes, cuyo macho tiene una larga melena en la nuca y en el cuello, y que es propio de África (uno de los cinco continentes): La leona es de menor tamaño que el león. 2 Persona valiente y atrevida: Los soldados eran unos leones $y$ ganaron la batalla. 3 || león marino; (macho/hembra) Mamífero marino de cuerpo en forma de huso, extremidades transformadas en aletas, que generalmente se alimenta de peces: Una de las diferencias entre las focas y los leones marinos es que estos tienen orejas visibles y las focas no.

b) Con los registros de uso se acotaba el uso de las palabras que tienen un valor determinado. Los valores anticuado (ant.), coloquial (col.), eufemístico (euf.), poético (poét.), despectivo (desp.), vulgar (vulg*) y vulgar malsonante (vulg. malson.) aparecen en aquellas acepciones cuyo registro de uso es restringido pero que los estudiantes extranjeros podrían encontrar en textos de uso actual. Veamos algunos ejemplos:

$>$ Anticuado:

a+fei-te s.m. ant. $\rightarrow$ cosmético.

o+tro+ra adv. ant. En otro tiempo: Otrora, se celebraban en el pueblo grandes fiestas.

brí+o s.m. 1 Fuerza con la que algo crece o se desarrolla o con la que se ejecuta una acción: Irrumpió con brío en medio de la reunión. + SIN. pujanza. 2 Energía, firmeza y decisión con que se hace algo: Tienes que estudiar con más brío. 3 Garbo y energía: No todos los actores caminan con ese brío. 4 || voto a bríos; ant. Juramento que expresaba cólera: ; Voto a bríos, que no baré tal cosa!

Coloquial:

a+lu+ci+nar v. 1 Padecer alucinaciones: La droga te hace alucinar y perder el control. 2 Sorprender, deslumbrar, o producir o experimentar asombro: Me alucina que seas capaz de pensar eso de mí. No dejo de alucinarme cuando te veo desenvolverte con esa soltura. + Está muy extendido su uso como intransitivo: Aluciné al verlo. 3 Ofuscar, engañar o seducir haciendo que se tome una cosa por otra: No te dejes alucinar por la palabrería de ese donjuán. 4 col. Equivocarse o desvariar: Si piensas eso de mí, tú alucinas. + En esta acepción, se usa más como verbo intransitivo. + Conjug. $\rightarrow$ HABlar (4). + Fam. alucinador(dora), alucinante.

ma+rrón (pl.marrones) adj.inv./s.m. 1 Del color de la cáscara de la castaña o con tonalidades castañas: El chocolate con leche es de color marrón. $\mathbf{s}_{\mathrm{s}} \mathrm{m} .2$ col. Lo que resulta desagradable o molesto: Tener que hacer lo que no me gusta es un marrón.

Eufemístico:

ne+ce+si+dad s.f. 1 Lo que es imprescindible o necesario: Nadie duda de la necesidad de estas reformas. 2 Impulso irresistible: Sentí la necesidad de abrazar a mi madre. 
3 Falta de lo necesario para vivir, esp. de alimentos: pasar necesidades. 4 Peligro o situación difícil que requieren una pronta ayuda: En sus necesidades acudía a Dios por medio de la oración. 5 euf. Evacuación de la orina o de los excrementos: Fue al servicio a hacer sus necesidades. o Se usa más en plural. 6 || de primera ; básico o imprescindible, esp. para una vida digna: La leche, el azúcar y el pan son artículos de primera necesidad.

gi.li+puer.tas (pl. gilipuertas) adj.inv./s.com. euf. $\rightarrow$ gilipollas.

\section{$>$ Poético:}

ca+lla+do, da adj. 1 (ser/estar) Poco hablador y reservado: Es tan callada que nunca sé lo que le pasa. Últimamente estás muy callado y pensativo. 2 poét. Silencioso o sin ruido: una noche callada. 3 || dar la callada por respuesta; col. No querer responder: Cuando le pedí explicaciones, me dio la callada por respuesta.

cre+pús+cu+lo s.m. 1 Claridad que hay desde que empieza a amanecer hasta que sale el Sol, y desde que se empieza a poner hasta que es de noche: El crepúsculo daba al jardin un aspecto triste. 2 Tiempo que dura esta claridad: Cuando conduzco durante el crepúsculo llevo encendidas las luces de cruce. 3 poét. Decadencia: Escribió sus más bellos poemas en el crepúsculo de su vida.

\section{Despectivo:}

ca+chi+va+che s.m. 1 Mueble o utensilio, esp. los de una casa y si están desordenados: Tenemos que ordenar todos los cachivaches de la cocina. 2 desp. Trasto u objeto en desuso, viejo o inútil: Esta vieja máquina de coser es un cachivache. + Se usa más en plural. + Se usa mucho como palabra comodín para designar de manera imprecisa un objeto.

ser •món (pl, sermones) s.m. 1 Discurso u oración de carácter didáctico que predica el sacerdote ante los fieles: El sermón del domingo tratará de la caridad. 2 col. desp. Amonestación, reprensión o consejo, esp. cuando resultan largos y pesados: El profesor me echó un sermón por llegar tarde a clase.

Vulgar:

pu+ta+da s.f. vulg. Hecho que causa un perjuicio, esp. si es malintencionado: iQué putada no poder ir de vacaciones! + SIN. faena.

a.jun+tar $\square_{\text {v. }} 1$ vulg. $\rightarrow$ juntar. 2 col. Ser amigo: Ya no te ajunto. o Es característico del lenguaje infantil. $z$ prnl. 3 vulg. Referido a una persona, vivir con otra con la que mantiene relaciones sexuales sin estar casada con ella. + Conjug. $\rightarrow$ HABLAR (4).

\section{Vulgar malsonante:}

des+co+jo+nar+se v.prnl. vulg.malson. Reírse mucho. + Conjug. $\rightarrow$ Hablar (4). + Fam. descojonamiento. 
jo+der $\mathbf{v} 1$ vulg.malson. $\rightarrow$ copular. 2 vulg.malson. Fastidiar o molestar mucho. $z$ interj. 3 vulg.malson. Expresión que se usa para indicar extrañeza, sorpresa, admiración o disgusto: joder, qué caro es este coche! + Como verbo, conjug. $\rightarrow$ BEBER (5).

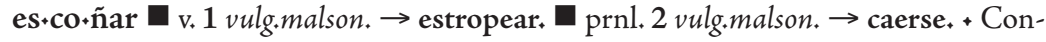
jug. $\rightarrow$ HABLAR (4).

c) Con las marcas de materia, en cambio, se especificó la disciplina en la que se utiliza la palabra marcada. Por ejemplo, la palabra decrescendo tiene la marca Mús., pues es una palabra propia del mundo de la música; o la palabra dicotiledóneo, que está marcada con BoT., es propia de la botánica (marcas que no hicimos extensivas ni a banyo, aunque sea un instrumento musical, ni a árbol, aunque este término designe un ser del mundo vegetal).

d) Las definiciones intentaron ser claras y precisas, antes que exhaustivas, a fin de facilitar al estudiante la comprensión. No contenían remisiones innecesarias sino que cada artículo se concebía como una entidad independiente que contenía toda la información necesaria para la correcta comprensión del término.

Fueron redactadas según unos modelos tipo, lo que daba una gran coherencia interna al cuerpo del diccionario (véanse por ejemplo, las unidades de medida, los instrumentos musicales, los cargos y las profesiones, etc.).

El problema del contorno se resolvió en la definición de verbos y adjetivos con la fórmula Referido a....

En el caso de los adjetivos, en ese contorno se explicitaba el tipo de sustantivo al que dicho adjetivo puede acompañar (ejemplo: salvaje no significa lo mismo referido a un animal, a una planta o a un terreno):

sal+va+je adj.inv, 1 Referido a un animal, que no es doméstico o que no vive totalmente condicionado a las personas: Los leones son animales salvajes. 2 Referido a una planta, que se ha criado en el campo de forma natural y sin cultivo: Este campo está lleno de bierbas y arbustos salvajes. 3 Referido a un terreno, que es abrupto y está sin cultivar: Esta es zona de monte salvaje. 4 col. Incontrolable o irrefrenable: una salvaje subida de precios. adj./s.com. 5 desp. Que mantiene formas primitivas de vida y no se ha incorporado al desarrollo de la civilización: En el continente africano aún quedan tribus salvajes. El contacto con los salvajes me enseñó a amar la naturaleza. 6 col. Obstinado, de poca inteligencia o que no tiene educación: Es tan salvaje que escribe 'bodega' con ' $v$ '. Solo los salvajes como tú responden con gruñidos cuando se les saluda. 7 col. Cruel o inhumano: El asesino cometió un acto salvaje con su víctima. Quemar a un gato es cosa de salvajes.

En el caso de los verbos, la fórmula permitía extraer el sujeto, el complemento directo o el complemento preposicional regido (ejemplo: existen diferen- 
cias apreciables entre alimentar a un ser vivo, alimentar un mecanismo, alimentar el fuego o alimentar un sentimiento):

a+li-men+tar v. 1 Referido a un ser vivo, proporcionarle alimento: Un buen filete te alimentaría más que todas esas chucherías. Las plantas se alimentan por las raíces. 2 Referido esp. a un mecanismo, proporcionarle lo que necesita para seguir funcionando: Esta batería alimenta todo el circuito. Este motor se alimenta con gasolina. 3 Referido esp. al fuego, servir para mantenerlo o para sostenerlo: Los troncos alimentan la hoguera. 4 Referido esp. a un sentimiento, avivarlo o fomentarlo: No alimentes mi desesperación con tu pesimismo. + Conjug. $\rightarrow$ Hablar (4).

e) Sinónimos y antónimos: Se recogían los principales sinónimos y antónimos del español actual. Se especificaba en cada caso si se referían a una acepción determinada o a toda la palabra.

cu+chi+lla+da s.f. Corte hecho con un cuchillo o con un arma blanca: Hubo una pelea $y$ le dieron varias cuchilladas en el pecho. + SIN. cuchillazo.

cu+chi+lla+zo s.m. $\rightarrow$ cuchillada .

f) Hay ejemplos de uso prácticamente en todas las definiciones. Cuando hay varias categorías gramaticales en una misma acepción, se dan varios ejemplos para que el alumno de español encuentre en cada artículo no solo los diferentes significados de cada palabra sino también cómo se usa.

le+ón, o+na (pl. leones, nas) s. 1 Mamífero felino y carnicero de pelo amarillo rojizo, dientes y uñas fuertes, cuyo macho tiene una larga melena en la nuca y en el cuello, y que es propio de África (uno de los cinco continentes): La leona es de menor tamaño que el león. 2 Persona valiente y atrevida: Los soldados eran unos leones y ganaron la batalla. 3 || león marino; (macho/hembra) Mamífero marino de cuerpo en forma de huso, extremidades transformadas en aletas, que generalmente se alimenta de peces: Una de las diferencias entre las focas y los leones marinos es que estos tienen orejas visibles y las focas no.

g) Muchas palabras derivadas no aparecen en los diccionarios, salvo que sea conveniente su inclusión porque hayan adquirido significados distintos del primer sentido: mesilla debe aparecer como lema porque, además de ser un diminutivo de mesa, tiene otro significado más específico. En este diccionario las palabras derivadas se recogían bajo el epígrafe FAM. El estudiante de español podrá comprender estas palabras con la ayuda de los sufijos que aparecen en el corpus del diccionario. Por ejemplo, palabras como predecible, acaloramiento, radicalización, caballerosidad, calumniador o paralizante se encuentran bajo el epígrafe FAM., pues con el significado de los sufijos correspondientes son fácilmente deducibles de predecir, acalorar, radicalizar, caballeroso, calumniar o paralizar, respectivamente. 
pre+de+cir v. Referido a algo que va a suceder, avisarlo o anunciarlo con antelación: La meteoróloga predijo temperaturas suaves para el fin de semana. + Irreg.: Su participio es predicho; $\rightarrow$ PREDECIR (6I). + Fam. predecible.

a+ca+lo+rar $\square$ v. 1 Dar o tener calor: Subir estos muebles por la escalera acalora a cualquiera. prnl. 2 Excitarse en una conversación o en una disputa: No te acalores $y$ habla con tranquilidad. o Conjug. $\rightarrow$ HABLAR (4). + Fam. acaloramiento.

ra+di+ca+li+zar v. Volver más radical, inflexible, extremo o intolerante: Ese partido se ha radicalizado mucho. + La $z$ se cambia en $c$ delante de e $\rightarrow$ utilizar (79). + Fam. radicalización.

ca+ba+lle+ro+so, sa adj. (ser/estar) Característico de un caballero por su cortesía, generosidad o nobleza: Fue muy caballeroso que me ayudases. Has estado muy caballeroso y formal en la ceremonia inaugural. + Fam. caballerosidad.

ca+lum+niar v. 1 Atribuir falsamente y con el fin de perjudicar palabras, actos o malas intenciones: No sé qué quiere conseguir calumniándole así. 2 DER. Acusar falsamente de haber cometido un delito perseguible de oficio: Si le calumnias, te puede demandar. + La $i$ nunca lleva tilde. + Conjug. $\rightarrow$ Hablar (4). + Fam. calumniador(dora), calumnioso(sa).

pa+ra+li+zar v. 1 Causar parálisis: Una enfermedad vírica paralizó sus piernas. 2 Referido esp. a una acción o a un movimiento, detenerlos, entorpecerlos o impedirlos: Paralizaron las obras porque no tenían permiso municipal. + La $z$ se cambia en $c$ delante de $e \rightarrow$ utilizar (79). + Fam. paralizante, paralizador(dora).

b) La inclusión de notas y observaciones sobre el uso de las palabras permite completar la información gramatical que, de forma implícita, impregna todo el diccionario:

Información ortográfica: permite distinguir las diferentes variantes ortográficas de una misma palabra (bierba/yerba, trascendencia/transcendencia) o llama la atención sobre la existencia de palabras homófonas (vaca/baca, vasto/ basto)

hier+ba (tb. yerba) s.f. 1 Planta de pequeño tamaño y de color verde que crece en un terreno, esp. el que sirve de alimento al ganado: Hay que arrancar las hierbas del patio. Las vacas comen hierba. 2 arg. Marihuana: Nunca he fumado bierba.

pl. 3 col. Conjunto de plantas usadas como condimento, para hacer infusiones o para la elaboración de algunos productos: un ramito de bierbas aromáticas; una infusión de hierbas. 4 || como la mala ; col. Muy deprisa: La envidia creció como la mala bierba. o Como la mala bierba se usa más con los verbos crecer, extenderse o equivalentes. || finas hierbas; las que se pican muy menudas y se usan como condimento: paté a las finas hierbas. $\| \sim$ buena; $\rightarrow$ hierbabuena. $\|(\sim)$ luisa; la de olor agradable, cuyas hojas se toman como infusión tónica, estomacal y digestiva. 
yer+ba s.f. $1 \rightarrow$ hierba. $2 \| \sim$ (mate); 1 Árbol de tronco recto, copa densa y hojas de color verde oscuro brillante. 2 Hojas secas de este árbol que se usan para preparar el mate: una infusión de yerba.

va+ca s.f. 1 Hembra del toro: una vaca lechera. 2 Carne de este animal: un filete de vaca. $3 \|$ loca; col. La que está afectada por una enfermedad degenerativa del sistema nervioso central: el mal de las vacas locas. $\| \sim$ marina; (macho/hembra) Mamífero herbívoro acuático de cuerpo grueso y piel grisácea de gran espesor, labio superior muy desarrollado y cuya carne y grasa son muy estimadas: La vaca marina vive en las desembocaduras de los grandes ríos. + SIN. buey marino, manatí. || vacas flacas; col. Época de dificultades y de escasez: Como lleguen las vacas flacas no podrás gastar tanto dinero. || vacas gordas; col. Época de prosperidad económica: En época de vacas gordas todos estamos contentos. + Dist. de baca (de un coche).

ba+ca s.f. En un automóvil, soporte que se coloca sobre el techo y que sirve para llevar bultos: una baca para los esquís. + SIN. portaequipajes. + Dist. de vaca (animal).

Información morfológica: aporta una completa información sobre masculinos, femeninos, formas irregulares, plurales, etc.

buen adj. $\rightarrow$ bueno. o Apócope de bueno ante sustantivo masculino singular: un buen chico; un buen libro.

le+ón, o+na (pl. leones, nas) s. 1 Mamífero felino y carnicero de pelo amarillo rojizo, dientes y uñas fuertes, cuyo macho tiene una larga melena en la nuca y en el cuello, y que es propio de África (uno de los cinco continentes): La leona es de menor tamaño que el león. 2 Persona valiente y atrevida: Los soldados eran unos leones $y$ ganaron la batalla. 3 || león marino; (macho/hembra) Mamífero marino de cuerpo en forma de huso, extremidades transformadas en aletas, que generalmente se alimenta de peces: Una de las diferencias entre las focas y los leones marinos es que estos tienen orejas visibles y las focas no.

a+li-sar v. 1 Poner liso: He alisado un poco la camisa. 2 Referido al pelo, ponerlo liso pasando el peine o la mano: Se miró en el espejo y se alisó un poco el pelo. + ANT. ondular. + Conjug. $\rightarrow$ Hablar (4). + Fam. alisamiento.

chu+pa+tin+tas (pl. chupatintas) s.com. col. desp. Oficinista: Nos atendió un chupatintas que no resolvió nada.

graffiti s.m.pl. $\rightarrow$ grafito. + Pron. [grafíti]. + Es un plural italiano, y su singular es graffito: incorr. *un graffiti.

gra+fi-to s.m. 1 Variedad de carbono cristalizado, compacto, opaco, de color negro y de brillo metálico: Las minas de los lápices son de grafito. 2 Letrero o conjunto de letreros murales de carácter popular, escritos o pintados a mano: Ha pintado un grafito con aerosoles de varios colores. 
$>\quad$ Información sintáctica: ayuda al estudiante de español a crear frases de forma correcta informando, por ejemplo, de los regímenes de construcción verbal o sobre la construcción de los adjetivos con los verbos ser o estar

a+lar+de+ar v. Hacer alarde u ostentación: Le gusta alardear de sus riquezas. + Conjug. $\rightarrow$ HABlAR (4) + Constr. alardear DE algo.

prin+go+so, sa adj. (ser/estar) Que está grasiento y pegajoso: Ten cuidado, que ese producto es muy pringoso. Las baldosas de la cocina están pringosas.

$>$ Información semántica: enriquece el léxico con matizaciones de los diferentes significados de las palabras

$>$ Información cultural: aporta información enciclopédica sobre realidades actuales que pueden resultar útiles al estudiante de español

\subsection{Sobre otros complementos informativos}

$>\quad$ En el centro del diccionario se ofrecía al estudiante de español una guía de conversación de 64 páginas con las principales situaciones con las que tendrá que enfrentarse cuando se encontrara en países de habla española: desde cómo pedir un café con leche (un tinto, en Colombia) hasta cómo reservar la habitación en un hotel, cómo escribir una carta, o qué frases emplear para pedir disculpas.

Además, en las páginas centrales había un cuadernillo con todos los modelos de conjugación verbal, que constaba de una brevísima introducción sobre el uso del verbo en España y en América Latina, seguida de los principales modelos de conjugación verbalः verbos auxiliares, verbos regulares, verbos en pasiva, verbos pronominales, verbos defectivos y verbos irregulares. Desde el cuerpo del diccionario se remitía a esos modelos verbales (no solo a los irregulares).

a+lar+de+ar v. Hacer alarde u ostentación: Le gusta alardear de sus riquezas. + Conjug. $\rightarrow$ HABLAR (4).+ Constr. alardear DE algo.

\section{Diez años después... Migración al ámbito digital}

Diez años han pasado desde entonces. Y, para empezar, en esos diez años el mundo de las obras de referencia ha migrado al ámbito digital.

El pasado sábado 6 de abril de 2012, José Antonio Millán (al que muchos consideramos auténtico gurú del mundo de la consulta en España) publicaba en Babelia un magnífico artículo sobre este fenómeno. Partiendo de una anécdota sobre el músico Schönberg (un músico precoz, hijo de un zapatero, que a los dieciocho años tuvo que esperar a que su familia comprara el volumen correspondiente a la letra $\mathrm{S}$ del Meyers Lexicon para poder conocer bajo la entrada 
sonata cómo estructurar un cuarteto), comenta lo que supondrá en el futuro (en el hoy, de hecho) la desaparición en papel de, nada menos que ¡la enciclopedia Britannica!:

No es el único caso pero sí el más famoso.... Una categoría de obras condenadas a la extinción ha sido la de «por si acaso»ः uno adquiría los tomos de una enciclopedia o los de un diccionario por si un día necesitaba algún dato. Hoy se limita a consultar por línea la palabra que busca. (Millán 2012:2)

El propio procedimiento de consulta ha cambiado (no solo la consulta de diccionarios y enciclopedias). De hecho, lo mismo ha ocurrido ya con esos miles de páginas que en todas las casas ocupaban un lugar establecido en el que un volumen ofrecía miles de números de teléfonos alfabetizados, bien por el apellido bien por las calles de la cuidad donde uno vivía; o con las obras legales desde que, ya hace más de tres años, el BOE es solo digital. Millán señala que ese cambio no se ha dado sin reticencias (señala cómo, de hecho, en la reciente campaña electoral, los políticos aún seguían apareciendo en televisión con el tradicional fondo tranquilizador de una biblioteca a sus espaldas). Pero, con reticencias o sin ellas, el cambio ya ha sido; ya se ha dado; ya es. De hecho, las guías turísticas que los jóvenes usan en sus desplazamientos no son ya guías en papel, sino sistemas de GPS que se pueden llevar en el móvil; y los diccionarios con que nuestros hijos viajan al extranjero no son diccionarios en papel sino listas multilingües de equivalencias léxicas en soporte electrónico.

El pasado 20 de marzo de 2012, los medios de comunicación recogían esta noticia: «Niños y jóvenes confían más en Google que en sus maestros y padres» ${ }^{5}$. Bajo este título, se ofrecían los resultados de una encuesta realizada en febrero de 2012 en el Reino Unido entre niños y jóvenes de ambos sexos, de entre 6 y 15 años de edad. Y del hecho de que el $91 \%$ de los encuestados usara el buscador como primera opción, se deducía, creo que erróneamente, que los más afectados eran enciclopedias, diccionarios, padres y profesores, pues los niños ya no se acuerdan de ellos para consultar dudas.

Maticemos: Resulta sorprendente (y así se señalaba en la noticia) que una cuarta parte de los niños que participaron en el estudio no sepan ya qué es una enciclopedia (el 10\% creyó que era un utensilio de cocina) y que más de la mitad de ellos no haya usado jamás una enciclopedia o que el 19\% jamás haya visto ni manejado un diccionario impreso. Pero de esa sorpresa no debe deducirse que los mecanismos psicológicos de búsqueda hayan cambiado (¿quién de los aquí presentes preguntó en su casa a sus padres o en el aula a sus profesores el significado

5. Noticia disponible en: <http://www.educared.org/global/noticias-educativas > [Fecha de consulta: 13-022012]. 
de palabras vulgares, malsonantes o con fuerte contenido sexual?), sino que lo que ha cambiado es el entorno en el que buscar (antes viajábamos por las páginas de un diccionario, y había trayectos casi de obligado cumplimiento, como el que nos llevaba de puta a prostituta; de prostituta a ramera; de ramera a prostitución; y de prostitución a relación carnal (y allí se acababa el viaje, sin ningún resultado). Por no hablar del viaje que iba de polla a pene, de pene a miccionar, desde allí a orinar, y de allí a expeler... O de la frustración en la que sin duda acabábamos cuando nos adentrábamos por el turbador mundo de la lujuria o de la lascivia y acabábamos, de nuevo, en los indefinidos ( $y$ nunca mejor utilizada esta palabra) deleites carnales...

No ha cambiado la necesidad de buscar información (y el compromiso social de determinadas instituciones educativas o culturales para proporcionar esa información de forma adecuada). No ha cambiado, por tanto, nuestro compromiso educativo para formar a nuestros alumnos en un espíritu crítico: si antes les enseñábamos a distinguir buenos y malos diccionarios en papel, hoy habrá que enseñarles a diferenciar buenas y malas fuentes de información en la red. Y si antes les hablábamos de la conveniencia de consultar enciclopedias ilustradas para conocer con exactitud los referentes denotados por determinada palabra, ahora no tenemos por qué escandalizarnos si para averiguar qué es un pepino prefieren consultar Google imágenes antes que el DRAE, obra en la que el pepino no es sino el fruto de una «planta herbácea anual, de la familia de las Cucurbitáceas, con tallos blandos, rastreros, vellosos y de dos a tres metros de longitud, hojas pecioladas, pelosas, partidas en lóbulos agudos, flores amarillas, separadas las masculinas de las femeninas, y fruto pulposo, cilíndrico, de seis a doce centímetros de largo y dos a cinco de grueso, amarillo cuando está maduro, y antes verde más o menos claro por la parte exterior, interiormente blanco y con multitud de semillas ovaladas y puntiagudas por uno de sus extremos, chatas y pequeñas».

Millán (2012: 2) no se atreve a afirmar si todo son ventajas en «este nuevo mundo de difusión incorpórea de obras». De hecho, no tiene reparos en reconocer que desconoce la respuesta. Y eso mismo nos pasa a los editores de obras lexicográficas. El procedimiento de la consulta ha cambiado. Y eso es un hecho. Ya no se almacena información; se exige que la información cuelgue de una nube y que esté permanentemente actualizada. Un buen manejo de la ordenación alfabética ya no es necesario para un buen manejo de las obras de consulta; de hecho, en un buen diccionario digital se exige viajar por hipertexto (si en una definición leemos que el pepino es una cucurbitácea, exigiremos que al pinchar sobre esa palabra nos aparezca el lema cucurbitáceo, a). Tampoco importa tanto saber buscar la forma canónica de un artículo: aunque la mayoría de los diccionarios actuales en la red 
no nos ofrecen la entrada sé (forma flexiva de saber o de ser), es cuestión de poco tiempo que, por debajo de la caja de búsqueda, ruede un buen lematizador que permita a la máquina reconocer que al escribir ese sé lo que estemos buscando sea el presente del verbo saber o el imperativo del verbo ser.

Porque sí, en estos diez años se ha consolidado la migración de las obras de referencia al mundo digital. Acabó ya la acumulación del «por si acaso» y ha empezado ya la consulta del «No sé, ahora te lo busco». Y es en este contexto en el que queremos traer a colación un encuentro que el pasado 22 de marzo, la Fundación BBVA organizó en Madrid entre los profesores Raffaele Simone, catedrático de la Universidad de Roma, y el profesor Ignacio Bosque, miembro de la Real Academia Española y Catedrático de Lengua española en la Universidad Complutense de Madrid. El tema del encuentro era Diálogo de lingüistas: qué hacen y para qué sirven. Y entre las muchas afirmaciones dignas de comentario que allí se vertieron (como, por ejemplo, cuál será el papel de la norma dentro de treinta años, cuando ya el universo de internet sea una realidad cotidiana para todos los hablantes de español de cualquier parte del mundo), de repente nos vimos coincidir con aquellos dos lingüistas en su planteamiento del aprendizaje (y, por tanto, de la enseñanza) de segundas lenguas. Porque en aquel encuentro, y con miras a la eficacia en el tiempo y en el rendimiento, lo que se defendía era un aprovechamiento aplicado de la lingüística contrastiva hasta el punto de llevarlos a afirmar (y permítasenos que simplifiquemos aquí sus declaraciones) que no creían en el español para extranjeros, por ser este un concepto demasiado abarcador; y sí, en cambio, en español para italianos, español para japoneses, español para hablantes de inglés, etc.

Y para reforzar este planteamiento propusieron algunos ejemplos: esas cuestiones de gramática del español que aparecen en cualquier manual de español para extranjeros (las diferencias entre canté y cantaba; o entre ser y estar, por ejemplo) pero que no pueden ser trabajadas igual si los estudiantes son de lengua materna italiana o china o árabe. De hecho, un italiano no encuentra ninguna dificultad en aprender la diferencia entre canté y cantaba (un japonés, en cambio, muchísima), y sí encuentra dificultad en el uso (no en la gramática) de la pasiva, mucho menos frecuente en español que en su lengua materna.

$¿ Y$ qué hacemos aquí disertando, si estamos diciendo que no creemos en el concepto ELE? Pues intentamos, simplemente, exponer por qué siempre que fuera posible deberíamos reivindicar una enseñanza de español para italianos, distinta de una enseñanza de español para hablantes de inglés, o para hablantes nativos de francés, o para estudiantes chinos, o para estudiantes que tengan el árabe como lengua materna... 
No estamos hablando de un español distinto para cada uno de estos grupos, sino de unos métodos de enseñanza distintos en función de las distintas necesidades de aprendizaje que tiene cada uno de estos grupos según cuál sea su lengua materna. Y, si no, baste como ejemplo el hecho de que la dificultad de aprender una palabra dependa de su relación con la correspondiente palabra en L1; como señala Ainciburu (2007), cognados, palabras nuevas y falsos amigos siguen ese orden de dificultad en el aprendizaje. ${ }^{6}$

¿Y qué podemos hacer, entonces, para superar esta crisis? Como nos recuerda Ricardo Soca en su página $w^{2} b^{7}$ ( $y$ como nos recuerdan, o nos intentan recordar cada día nuestros jefes en la empresa), crisis puede ser sinónimo de oportunidad:

Si alguien dice que $[\ldots]$ está 'en crisis', no es necesariamente una mala noticia; una crisis puede ser el anuncio de cambios favorables y del fin de problemas y dificultades. El Diccionario atribuye a esta palabra el significado de un cambio brusco - para bien o para mal- en el curso de una enfermedad o de procesos físicos, históricos o espirituales. Crisis se aplica también a los momentos decisivos de situaciones graves o de repercusiones importantes.

De acuerdo, oportunidad, pero ¿para qué? Creemos que, antes que nada, para aprovechar el medio online. Y tenemos ya muchos buenos ejemplos de ello. Citemos, al menos, dos: los dos diccionarios online dirigidos a estudiantes de español como lengua extranjera en los que colabora el CIESE (Centro Internacional de Estudios Superiores del Español) de Comillas: un diccionario monolingüe de verbos dirigido a estudiantes de nivel avanzado y pensado principalmente para la producción, dirigido por el Instituto Universitario de Lingüística Aplicada de la Universidad Pompeu Fabra (DAELE); y el diccionario de partículas discursivas del español, dirigido desde el Departamento de Filología Española de la Universidad de Valencia (DPDE).

Pero, sobre todo, creemos que estamos ante una oportunidad de innovar, y de crear, y de apostar por abrir nuevos caminos en la lexicografía.

6. Recordemos que los cognados son palabras que comparten significado, ortografía y pronunciación en dos lenguas distintas; y que falsos amigos, en cambio, son las palabras que, a pesar de tener significados distintos, pueden escribirse o pronunciarse de manera similar en dos o más idiomas. Y recordemos también, fiándonos en nuestra propia experiencia como aprendientes de una lengua distinta al español, cómo son estas últimas palabras las que más nos cuesta aprender (cuántas veces hemos malinterpretado el être constipé del francés, y hemos entendido 'constipado' donde deberíamos entender 'estreñido'; o el ser sensible del inglés, cuando ser sensato nada tiene que ver con ser sensible...).

7. <http://www.elcastellano.org> 


\section{Conclusiones: Una apuesta de futuro}

Y acabamos ya con un sueño, y con una invitación a imaginar...

Imaginemos un diccionario monolingüe de español, base de un proyecto más amplio y ambicioso:

- Imaginémoslo, antes que nada, en soporte digital y con consulta en la web (sin límites de espacio, por tanto, para incluir información)

- Imaginémoslo con un lemario graduado por niveles, en el que aparezcan marcadas las palabras y términos correspondientes a los niveles A, B y C del marco curricular europeo.

- Imaginémoslo con pronunciación (oral), no con transcripción fonética (escrita).

- Con separación silábica en los lemas.

- Con definiciones claras y precisas, redactadas básicamente con un vocabulario mínimo definidor.

- Con ejemplos en todas las definiciones; y con varios ejemplos para cada acepción cuando con ello aclaremos usos gramaticales distintos.

- Con notas y observaciones sobre peculiaridades ortográficas, morfológicas, sintácticas, de registro y de uso.

- Con ilustraciones (sueltas y temáticas)

- Con remisión a cuadros gramaticales (con modelos verbales para verbos regulares e irregulares)

- Con una Guía de conversación que resuma en un compendio el léxico pasivo asociado a las distintas situaciones comunicativas más estándar.

- Y todo él con unos enlaces de hipertexto que nos lleven en un solo clic de palabra en palabra por todo el diccionario.

- Y todo esto, imaginémoslo como punto de partida para la elaboración de distintas versiones de diccionarios semibilingües: en función de cuál sea la lengua materna de los destinatarios a los que va dirigido, se añadirá la traducción al final de cada acepción.

- Soñemos que en cada una de esas versiones, se incluyen notas y observaciones obtenidas de los estudios de lingüística contrastiva que hayan puesto de manifiesto cuáles son los errores más frecuentes en los hablantes de esa lengua cuando aprenden español. (Soñemos que los DELE del Instituto Cervantes son el banco de datos para obtener esa información; y soñemos que el acceso a dichos datos está abierto a todos).

- Y soñemos que a cada una de esas versiones se le añadirá una segunda mitad del diccionario, bilingüe, en la que desde la lengua materna se ofre- 
cerá la traducción al español a fin de dar respuesta a las necesidades de producción del usuario

¿Es este sueño un proyecto viable? Sí, sin duda; en el aspecto lexicográfico. Veremos en el aspecto económico y de rentabilidad...

En su artículo del año 2004, Rushtaller concluía sus Consideraciones reivindicando nuevos diccionarios bilingües con tantos lemas y con artículos tan detallados y completos como solía ser propio de los diccionarios monolingües. Y afirmaba (en una nota a pie de página):

Tales proyectos son perfectamente viables económicamente, al menos para los idiomas extranjeros en cuyo dominio el número de aprendientes de español como lengua extranjera es elevado, pues aunque los diccionarios monolingües tienen asegurado un mercado geográficamente más amplio al dirigirse a cualquier aprendiz independientemente de su lengua materna, la clara preferencia de los usuarios por los diccionarios bilingües compensa la mayor reducción del área de comercialización.

No es tan sencillo. Y volvemos a apoyar esta reflexión en la propia experiencia. El gran problema que tenemos en las editoriales lexicográficas (las que hacemos diccionarios para venderlos y amortizar, al menos, la inversión) es justificar la rentabilidad de las inversiones. Y la justificación de la viabilidad económica de un proyecto de este tipo es difícil. Pero no perdemos la esperanza de abordarlo en una fecha no muy lejana. Dejemos ya para otro momento (¿quizá para unas Jornadas Internacionales de sostenibilidad de proyectos editoriales?) el detalle concreto de los que consideramos que serían los pasos necesarios para abordar con éxito esta empresa.

\section{Referencias bibliográficas}

Águila Escobar, G. (2009). Los diccionarios electrónicos del español. Cuadernos de lengua española. Madrid. Arco/Libros.

Acuña, M.L. et alii (2009). "Actitudes frente a la lengua en la enseñanza de español a Extranjeros». Revista Nebrija de Lingüistica Aplicada a la Enseñanza de Lenguas. 6: 105. [Disponible en: <http://www.nebrija.com/revistalinguistica/revista_6/articulos_n6/biblioteca_3.pdf]. [Fecha de consulta: 13-02-2012>]

Ahumada, I. (2004). «Exigencias al diccionario monolingüe de aprendizaje». En: Lorenzo Berguillos, F. y Rihstaller, S. (coords.). La competencia 
lingüistica y comunicativa en el aprendizaje del español como lengua extranjera. Madrid. Edinumen: 83-96.

Ainciburu, M.C. (2007). La adquisición de léxico en las lenguas afines. El aprendizaje de cognados, falsos amigos y palabras nuevas por alumnos italianos de Espanol como Lengua Extranjera. Tesis doctoral. [Resumen disponible en <http:// www.nebrija.com/servicios/publicaciones/descargas/tesis-cecilia-ainciburu. pdf ]. [Fecha de consulta: 13-02-2012>]

Alvar Ezquerra, M. (dir.). (2000). Diccionario para la enseñanza de la lengua española. Barcelona. Bibliograf / Universidad de Alcalá.

- (2003). La enseñanza del léxico y el uso del diccionario. Cuadernos de Didáctica del español/LE. Madrid. Arco/Libros.

- (2012). Los diccionarios bilingües y el aprendizaje de la lengua. En: Congreso Mundial de Profesores de Español (COMPROFES). 21 de noviembre de 2011 [Disponible en <http://comprofes,es/videocomunicaciones $>$ ] [Fecha de consulta: 13-02-2012].

Bargalló Escrivá, M. (1999). «La información gramatical en los diccionarios monolingües de aprendizaje». En: Orduña López, J.L. (1999): Así son los diccionarios. Lérida. Universitat de Lleida. Servicio de Publicaciones: 15-42.

Carriscondo F. (2012). «La edición de diccionarios de lengua española en el mundo hispánico: una lanza por Clave». Comunicación leída en el II Foro Editorial de Estudios Hispánicos y Americanistas (Universidad de Cádiz, 25 al 27 de abril de 2012) (en prensa).

[DPDL] Diccionario de partículas discursivas del español. [Disponible en: $<$ http:// www.dpde.es $>$ ] [Fecha de consulta: 13-02-2012].

[DAELE] Diccionario de verbos para estudiantes de ELE. [Disponible en: $<$ http $: / /$ www.ciese-comillas,es/es/investigacion/proyectos/diccionario-verbos-estudiantes-ele-daele >] [Fecha de consulta: 13-02-2012].

[DRAE] Real Academia Española. Diccionario de la Lengua Española. [Disponible en: <http://www.rae.es $>$ ]

García SAnz, E. (2009). El diccionario: su utilidad en el proceso de enseñanzaaprendizaje de ELE. Una vuelta más de tuerca. Memoria de Máster. En: Biblioteca 2011. 12. Universidad Antonio de Nebrija [Disponible en $<$ http:// www.educacion.gob.es/dctm/redele/Material-RedEle/Biblioteca $>$ ]. [Fecha de consulta: 13-02-2012]. 
Hernández Hernández, H. (1989). Los diccionarios de orientación escolar. Contribución al estudio de la lexicografía monolingüe española. Tübingen. Max Niemeyer Verlag.

- (1990). «Hacia un modelo de diccionario monolingüe del español para usuarios extranjeros». En: Martínez González, A. y De Molina Redondo, J. A. (eds.). El español como lengua extranjera: Aspectos generales. Actas deI I Congreso de ASELE. Granada. Universidad de Granada: 159-166.

- (2000). «El diccionario en la enseñanza de ELE (Diccionarios de español para extranjeros)». En: Martín Zorraquino, M. A. y Díez Pelegrín, C. (eds.). ¿Qué español enseñar? Norma y variación lingüísticas en la enseñanza de español a extranjeros. Actas del XI Congreso Internacional de ASELE. Zaragoza. Servicio de Publicaciones de la Universidad de Zaragoza: 93-103.

- (2001). «El diccionario informatizado como recurso en la enseñanza de ELE». En: Gimeno Sanz, A.M. (ed.). Tecnologías de la información y de las telecomunicaciones en el aula ELE. Actas del XI Congreso Internacional de ASELE. Valencia. Universidad Politécnica de Valencia: 191-199.

- (2005). «Quince años después: estado actual y perspectivas de la lexicografía del español para extranjeros». En: Castillo Carballo, M.A. et alii (eds.). Las gramáticas y los diccionarios en la enseñanza del español como segunda lengua: Deseo y realidad. Actas del XV Congreso Internacional de ASELE. Sevilla. Universidad de Sevilla: 465-472.

- (2008). «Retos de la lexicografía didáctica». En: Azorín Fernández, D. et alii (eds.). II Congreso Internacional de Lexicografía Hispánica. Alicante. Universidad de Alicante: 22-32.

- (2012a). «La variedad y la unidad del español en este diccionario». Enः Clave (2012): XV-XVIII.

- (2012b). «La lexicografía didáctica del español en Hispanoamérica: aspectos teóricos y descriptivos». En: Rodríguez González, F. (ed.). Estudios de lingüistica española. Homenaje a Manuel Seco. Publicaciones de la Universidad de Alicante: 277-305.

Gelpí Arroyo, C. (2003). «El estado actual de la lexicografía: los nuevos diccionarios». En* Medina Guerrera, A. M. (coord.). (2003). Lexicografía española. Lingüística. Barcelona. Ariel: 307-328.

Losada Aldrey, M.C.; I. Mas Álvarez (1998). «Hacia el diccionario monolingüe en el marco E/LE. Revisión de algunos aspectos de microestructura». En: Moreno Fernández, F. et alii: La enseñanza del español como lengua ex- 
tranjera: del pasado al futuro. Actas del VII Congreso Internacional de ASELE. Madrid. Universidad de Alcalá: 505-517.

Maldonado González, C. (dir.). (2002). Diccionario de español para extranjeros. Madrid. SM.

- (dir.). (2012). Clave. Diccionario de uso del español actual. 9a ed. Madrid. SM (1 ${ }^{\mathrm{a}}$ ed.ः 1997).

Martín Bosque, A. (2006). «Las locuciones en los diccionarios monolingües de aprendizaje de español lengua extranjera». Quaderni del CIRSIL. 5. [Disponible en <http://www.lingue.unibo.it/cirsil > ]. [Fecha de consulta: 13-022012].

- (2007). «El contorno lexicográfico en los diccionarios monolingües de E/LE: necesidades del usuario italiano». En: Lingüística Contrastiva tra italiano e lingue iberiche. Actas del XXIII Convegno AISPI. Palermo. 2005. Universidad de Palermo: 361-382.

Martín García, J. (1999). El diccionario en la enseñanza del español. Cuadernos de didáctica del español/LE. Madrid. Arco/Libros.

Martínez Navarro, M. R. (2005). «El diccionario de L2 que deseamos». En: Castillo Carballo, M. A. et alii (eds.). Las gramáticas y los diccionarios en la enseñanza del español como segunda lengua: Deseo y realidad. Actas del XV Congreso Internacional de ASELE. Sevilla. Universidad de Sevilla: 573-579.

Millán, J. A. (2012). «En la era de las obras tránsfugas», Babelia, 06/07.04.12: 2. [Disponible en <http://jamillan.com/librosybitios/transf.htm>]. [Fecha de consulta: 08-04-2012].

Moreno Fernández, F. (2000). «Diccionarios para el aprendizaje de lenguas extranjeras». En: Rushtaller, S. y J. Prado (eds.). Tendencias en la investigación lexicográfica del español. El diccionario como objeto de estudio lingüístico y didáctico. Huelva. Universidad de Huelva: 151-170.

Nomdedeu Rull, A. (2009). «Diccionarios en internet para el aula de ELE». Revista electrónica de Didáctica ELE [en línea], 15. [Disponible en: <http:// www.mepsyd.es/redele/Revista15/Nomdedeu_Diccionarios.pdf $>$ ] [Fecha de consulta: 13-02-2012].

Piedehierro, C. (2009). «La transferencia de instrucción. Un rasgo de la interlengua de aprendices francófonos de ELE». Revista Nebrija de Lingüistica Aplicada. 5 (3): 55-86.

Prado Aragonés, J. (2012). «Diccionarios monolingües para el aprendizaje de español como lengua extranjera: inclusión y marcación de americanismos en 
sus corpus». Káñina. 33. [Disponible en: <http://www.latindex.ucr.ac.cr/ kan012-02.php>]. [Fecha de consulta: 13-02-2012].

Rushtaller, S. (2004). «Consideraciones sobre los diccionarios monolingüe y bilingüe». En: Castillo Carballo, M.A. et alii (eds.). Las gramáticas y los diccionarios en la enseñanza del español como segunda lengua: Deseo y realidad. Actas del XV Congreso Internacional de ASELE. Sevilla. Universidad de Sevilla: $86-93$.

Rushtaller, S.; Gordón, M.D. (eds.) (2010). Diccionario y aprendizaje de español. Bern. Peter Lang.

SÁnchez López, I. (2011). Léxico, diccionario y enseñanza-aprendizaje de ELE: La rección verbal en los diccionarios monolingües de producción. Jaén. Universidad de Jaén. 